NBER WORKING PAPER SERIRS

A CONVEX MODEL OF EQUILIBRIUI GROWTH

Larry E. Jones

Rodolfo Manuelli

Working Paper No. 3241

NATIONAL BUREAU OF RCONOMIC RESBARCH 1050 Masaschusetta Avenue

Canbridge, MA 02138

Januaxy 1990

We would like to thank Roger Hodrick, Ken Judd, Ed Prescott, and Nancy Stokey for their generous comments. We also acknowledge very helpful conversations with Willian Brock and Hugo Hopenhayn. Remeining errors are ours, of course. Financial support fron NSF is gretefully acknowledged. The first author also acknowledges financial support fron The sloan Foundation. This paper is part of NBER's research progran in Growth. Any opinions expressed are those of the authors not those of the National sureau of Economic Research. 
NBER Working Paper \#3241

January 1990

\title{
A CONVEX MODEL OF EQUILIBRIUN GROWTH
}

\begin{abstract}
ABSTBACT
Our aim in this paper is to exposit a convex model of equilibrium growth. The model is strictly in the Solow tradition. The model lias two features which distinguish it from most other work on the subject. These are, first, that the model is convex on the technological side and, second, that fixed factors are explicitly included. The difference between our model and the standard single sector growth model lies in the fact that the marginal product of capital does not converge to zero as the level of inputs go to infinity. Existence and claracterization results are provided along with some preliminary analyses of taxation and international trade policies. It is shown that the long-run growth rate in per capita consumption depends, in the natural way, on the parameters describing tastes and technology. Finally, it is shown that some policies have growth effects while others affect only levels. It is demonstrated that in a free trade equilibrium with taxation national growth rates of consumption and output need not converge.
\end{abstract}

Larry E. Jones

J.L. Kellogg Graduate School of Management

Department of Managerial

Econonics and Decision Sclences

Northwestern UnIversity

Evanston, IL 60208
Rodolfo Manuelli

Graduate School of Business

Stanford University

Stanford, CA 94305-5015 


\section{Introduction}

Why do some countries grow quickly while others do not? Why is it that some countries seem endlessly mired in poverty while other similar ones suddenly take off in a period of exponential development? Is growth affected by the taxation and foreign trade policies of governments? Can a government, through appropriate choice of policy "trigger" a spurt of growth? To what extent can we trace the success of certain countries in recent years to explicit policies on the part of their governments?

These are important questions that have received considerable attention from scholars interested in growth and development. Specifically, there is a wealth of evidence describing episodes of growth and stagnation as well as the government policies in effect in each country. Corbo et al [1985], Krueger [1978], [1986] and Reynolds [1985] document national growth experiences and present detailed analyses of trade and macroeconomic policies.

In contrast, there is a relative paucity of purely theoretical studies of the causes of growth. The reason for this neglect is fundamental. The standard version of the natural class of models to look at have the property that in the long run there is no growth and that-under small discounting -output per capita converges to its steady state level independently of initial conditions (see, for example, Scheinkman [1976].)

More precisely, the standard version of the natural class of models at which to look (i.e., those of capital theory) have the property that the only potential sources of growth are sustained exogenous increases in factor supplies (e.g., population growth) and exogenously given technological change (see, for example, Solow [1957] and the resulting literature). Thus, except for the possibility of exogenous technological change, these models of growth lead one to the startling conclusion that there is no growth in per capita terms. Rather, depending on initial conditions, in simple versions there is growth until the capital stock reaches a steady state where things settle down permanently. This is true (roughly) independent of the discount rate and preferences.

In terms of the implications for cross country analysis, if countries are assumed to have the same preferences and technologies but are allowed to differ in terms of their endowments (initial conditions in this setting), the convergence results predict that country specific differences in output per capita will tend to disappear in the long run.

The fundamental problem with this literature is tliat when faced with the phenomenal sustained growth in per capita output that many countries have experienced, the only explanation the models 
have to offer is exogenous technical change; and they are silent about cross country differences. Of course, one cannot expect to obtain satisfactory answers to the questions raised above in this case. The natural fist step to remedy this problem is to try to endogenize the process of technical change. Unfortunately, at least if this is done in the most obvious way (i.e., through the introduction of a second capital good-knowledge), this avenue suffers from the same problems.

More recently, three different unodels of capital formation have been proposed to deal with this problem. These are the externality/increasing returns unodel discussed in Romer [1986], the model of human capital forination proposed in Lucas [1988], and the model of new goods introduction with learning by doing advanced in Stokey [1988] and Schmitz [1989]. These are al] variations on the more standard (i.e., Solowian) nodel of capital theory. They all, however, depart from the usual theory in one important way. This is that in their specification of technology, the three models all rely either on important nonconvexities in the production set or on the absence of fixed factors. ${ }^{2}$

Our purpose in this paper is twofold. We want to show that a natural generalization of the standard convex technology used in the early aualysis of growth models is sufficent to generate long run increasea in consumption per capita. Additionally, we show how different government policies can affect the long run behavior of the economy. In a multicountry setting different policies are shown to induce enough heterogeneity so that in a free trade equilibirum it is possible for the growth rates of consumption and output of any two countries to be permanently different.

In related work, Rebelo [1988] also analyzes a convex model of endogenous growth. He concentrates on special forms of preferences and technologies designed to give rise to optimal paths which have constant growth rates. This necessitates all assumption that fixed factors (e.g., labor) do not enter the production functions for investment goods. He also stresses the role that policy can play in determining the long run (i.e., growth) properties of the model and gives closed form solutions for growth rates in some cases.

To indicate why convex technologies are sufficent to generate growth, consider the savings decision of an individual with preferences given by the discounted present value of instantaneous utility. If the intereat rate equals the inverse of the discount factor, the individual chooses a smooth pattern of consumption over time. Because in a representative agent model individual and aggregate consumption coincide, aggregate consumption is stable over time-that is, there is no growth. On the other hand, if the interest rate exceeds the inverse of the discount rate there is an incentive to increase

2 These models are based on work done by Arrow [1962) and Uzawa [1965]. For an early analysis explicitly modeliting the role of endogenous technical change see Shell [1967] and [1973]. 
consumption in the future. The higher interest rate causes the time profile of consumption to be upward sloping. Then, it follows that to guarantee unbounded growth it is necessary to prevent the interest rate from falling to the level of the inverse of the discount factor.

A standard arbitrage condition is that the interest rate equals the marginal product of capital. It is then clear why the standard version of the neoclassical growth model cannot deliver long run growth: as the stock of capital per worker increases, its marginal product is assumed to decrease without bound and, hence, for some level of capital, it equals the inverse of the discount factor. At this point desired consumption is constant over time and the process of capital accumulation stops.

Note, however, that a convex technology requires only that the marginal product of capital is a decreasing function of its stock, and not that it decreases to zero as the amount of capital per worker grows without bound. The technologies that we study are generalizations of the idea that the marginal product of capital remains bounded, and are extensions of the linear technology pioneered by Gale and Sutherland [1968] and that were already considered by Solow [1956].

To understand how government policies can affect growth, consider a tax on saving (or more generally a tax on capital income). This lowers the after tax rate of interest and, consequently, flattens the desired time path of consumption. Of course, in a general equilibrium setting this results in lower growth.

Because capital accumulation decisions are ultimately controlled by the after tax rate of return it is possible for the growth rate of two countries-that have the same preferences and technology-to differ. The intuition is simple. Cousider two identical countries-a high tax and a low tax country. It can be shown that after one period the low tax country accumulates more than the high tax country. It follows that this lower rate of accumulation translates-under some circumstances-into a lower growth rate.

The analysis seerns to suggest that any policy that increases the rate of return to capital must have long cun effects. This, however, is not totally correct. The reason is that some changes can have only short term effects without changing the long run prospects of the economy. A natural example is given by considering an open economy. If trade policy has the effect of artificially increasing the price of capital goods, trade liberalization must increase the rate of return on investment and, hence, spur growth. Whether this effect is permanent or not depends on what other technologies individuals have access to in order to shift wealth over time. In particular, if there is international capital mobility it is possible that lowering trade barriers only results in growth up until the point 
where the domestic rate of return again equals the international rate of interest, with no long run changes.

This simple analysis highlights the complexity of the effects of government policies, and it shows that partially removing distortions need not increase the growth rate, even in cases in which the changes are in the right direction.

In this paper we concentrate on the analysis of tax and foreign trade policies not because they are the only ones that are relevant but because they seem a natural first step. As the paper shows, any distortion that increases the price of the relevant capital goods will have a negative impact on growth. Of course, monopoly power and a large number of regulatory policies can have this effect.

In the next section we introduce our notation and make a short digression on the standard version of the model from capital theory. Section 3 contains the existence and characterization results along with sufficient conditions for equilibrium with sustained growth. In section 4 we conduct a preliminary detailed analysis of a special case. In Section 5 we analyze the effects of distortionary taxes. Sections 6 and 7 contain extensions of the results to a simple dynamic model of international trade. Finally, we offer some concluding comments in Section 8.

\section{Notation and a Digression}

We will follow the standard capital theory notation. At each time period $t=1, \ldots$, there are $n+2$ goods available for use: labor, $l_{t}, n$ types of capital, $k_{t}$, and consumption, $c_{t}$. There is a single technology for turning capital and labor into output. This will be denoted by $F(k, \ell)$. For simplicity, we will assume that labor is supplied inelastically and that $\ell_{t}=1$ for all $t$. Define $f(k)=F(k, 1)$. Let $x_{t}=\left(x_{11}, \ldots, x_{n k}\right)$ denote investment at time $t$.

We will consider a representative consumer formulation with utility function given by $U\left(c_{1}, \ldots\right)=$ $\Sigma \beta^{t} u\left(c_{t}\right)$.

Thus, the problem faced by the consumer (social planner) is to choose $c_{t}, x_{t}, k_{t}$ to maximize $\Sigma \beta^{t} u\left(c_{t}\right)$, subject to

(1) $c_{t}+\sum_{i=1}^{n} x_{i t} \leq f\left(k_{t}\right)$;

(2) $k_{i t+1} \leq\left(1-\delta_{i}\right) k_{i 1}+x_{i t} \quad i=1, \ldots, n$;

(3) $x_{t}, c_{t}, k_{t} \geq 0$

(4) $k_{0} \geq 0$ given, 
where $0 \leq \delta_{i} \leq 1, i=1, \ldots, n$, is the depreciation rate.

Assume that $u$ and $f$ are concave and $C^{2}$ and note that we have followed the industry standard by assuming that there is linear depreciation.

To explain a key aspect of the standard model let $n=1$. Now assume that $\lim _{k \rightarrow \infty} f^{\prime}(k)=0$ (e.g., $F$ is any of the standard forms). Then the model is of the standard variety. If $\delta>0$, and $f^{\prime}(0)>\delta$, it follows that there is a (unique) $k^{*}>0$ such that $\delta k>f(k)$ for all $k>k^{*}$. It follows immediately that if $k_{0} \leq k^{*}, k_{t} \leq k^{*}$ and if $k_{0}>k^{*}$, that $k_{t}<k_{0}$ for all $t$. In particular, $k_{t}$ is necessarily bounded. Hence sustained growth is not feasible. (Actually, this only requires that $\lim _{k-\infty} f(k)<\delta$.)

In contrast to the approach outlined above, we will not assume that the marginal product of capital goes to zero as the stock of capital per worker increases without bound.

\section{A Version of the Model with Growth}

We now present conditions that guarantee the existence of a solution and then explore the possibility of long run growth.

Let $Y$ be the collection of feasible choices (i.e. infinite sequences of $x$ 's, $c^{\prime} s$ and $k$ 's). It follows from (2) -(4) that there exists a sequence of nonnegative constants $B_{t}$ such that $c_{t}, x_{t}, k_{i t} \leq B_{t}$ for all $t$ and all sequences in $Y$.

Proposition 1: Let $U=\Sigma \beta^{t} u\left(c_{t}\right)$ and suppose that $u$ is monotone increasing, continuous, bounded below and that there exists $a n \alpha>0$ and $\hat{U}<\infty$ with $\alpha \beta<1$ such that $u\left(B_{t}\right) \leq \hat{U}+\alpha^{\prime}$ for all $t$. Then the planner's problem of maximizing $U$ over the set $Y$ has a solution.

Proof: Note that, by assumption, $Y \subset \prod_{t=1}^{\infty}\left[0, B_{t}\right]^{n+2}$, which is compact in the product topology. Since $Y$ is closed (due to the continuity of $f$ ) it follows that it is compact.

It is then sufficient to show that $U$ is defined on all of $Y$ and that it is continuous in the product topology. That $U$ is well defined on $Y$ is immediate given the bound $B_{l}$. What is left to show is that $U$ has the requisite continuity properties. Let $c^{n}$ be a sequence of sequences converging to $c^{*}$ in the product topology. It follows that $c_{t}^{n} \rightarrow c_{t}$ for all $t$ and, because $u$ is continuous, that $u\left(c_{t}^{n}\right) \rightarrow u\left(c_{t}^{*}\right)$ for all $t$. Thus by the Lebesgue Dominated Convergence theorem $\left(\beta_{t} u\left(c_{t}^{n}\right)\right.$ is dominated by $\beta^{*} \widehat{U}+(\beta \alpha)^{t} \leq \gamma^{t}$ for some $\left.\gamma<1\right) \quad U\left(c^{n}\right) \rightarrow U\left(c^{*}\right)$ as desired.

The condition on the maximal growth rate of output is similar to that presented by Brock and Gale [1969] in the context of factor augmenting technical progress. Although it is possible to find a tighter 
bound than $B_{1}$, some restriction on the maximal growth rate of consumption is necessary, as the following example indicates.

Example: Let $f(k)=b k, u(c)=c^{1-\sigma} /(1-\sigma)$. Moreover, assume $\beta[(1-\delta)+b]^{1-\sigma}>1$. It is straightforward to verify that the sequence $c_{t}=\alpha b[(1-\delta)+(1-\alpha) b]^{2} k_{0}$ is feasible for all $\alpha$ (with $\left.k_{1}=[(1-\delta)+(1-\alpha) b]^{t} k_{0}\right)$ and that $\Sigma \beta^{t} u\left(c_{1}\right)=\infty$ if $\alpha$ is sufficiently small.

Thus, as long as per-period utility cannot grow too fast things are okay. Note that there are several obvious situations in which the conditions of the proposition are satisfied. First among these is when $u$ is bounded. Second is when the maximal feasible growth rate of consumption is less than $1 / \beta$. Note that neither of these is essential, however. If $u$ is of the form $u(c)=c^{1-\sigma} /(1-\sigma), \sigma>0$, the condition is satisfied as long as the maximal feasible growth rate in $\mathrm{c}$ is less than $(1 / \beta)^{1 /(1-\sigma)}$. (This example plays a central role in Lucas [1988].) Although we assumed that $u$ is bounded below, this is not necessary for the argument.

The next issue to examine is under what conditions the solution to the planner's problem displays long run growth. To do this we present a condition on the technology and the discount factor that is sufficient to generate long run growth.

\section{Condition G}

(i) Consider the model described by (1)-(4). In addition, assume that $f(k) \geq h(k)$, where $h$ is concave, homogeneoss of degree one and $C^{1} \quad \forall k \in \mathbb{R}_{+}^{n}$.

(ii) Assume that there exists a vector $\hat{k}_{\in} \mathbb{R}_{+}^{n}, \hat{k} \neq 0$, such that if $\hat{k}_{i}>0$

$$
\beta\left[h_{i}(\tilde{k})+1-\delta_{i}\right]>1 \quad i=1, \ldots, n .
$$

In the special case $n=1$, the production function must be of the type $f(k)=b k+g(k)$ with $\beta[b+1-\delta]>1$. Then the simplest example of the type of technologies we have in mind is that studied by Gale and Sutherland [1968] who considered $f(k)=b k$.

Condition $\mathbf{G}$ will not be satisfied if the representative consumer is very impatient (low $\beta$ ) or if the economy is not productive ( $f_{i}(k)$ must be bounded below along some ray). Next we prove that if condition $\mathbf{G}$ is satisfied, consumption grows without bound.

Theorem 1: Assume condition $G$ is satisfied. Then: any optimal solution $\left\{c_{i}^{*}\right\}$ is characterized by

(a) If there is a single capital good $(n=1), \lim c_{i}^{*}=\infty$, and investment is positive for all $t$. 
(b) In the case of multiple capital goods $\lim$ sup $c_{t}^{*}=\infty$.

Proof: To shorten the proof we first establish (b) and then indicate how to prove (a).

(b) It suffices to show that liminf $u^{\prime}\left(c_{i}^{*}\right)=0$. Suppose to the contrary that $\liminf u^{\prime}\left(c_{i}^{*}\right)=\bar{u}>0$. A standard manipulation of the first order conditions for the planner's problem shows that if $\left\{c_{i}^{*}, k_{i}^{*}\right\}$ is a solution it must satisfy

$$
u^{\prime}\left(c_{t}^{*}\right) \geq \sum_{s=1}^{\infty} \beta^{\prime}\left(1-\delta_{i}\right)^{-1} u^{\prime}\left(c_{t+\jmath}^{*}\right) f_{i}\left(k_{i+s}^{*}\right), \text { for all } t \text { and } i=1,2, \ldots, n .
$$

Given the assumption that $u^{\prime}\left(c_{i+\jmath}^{*}\right) \geq \bar{u}$, we have that

$$
u^{\prime}\left(c_{i}^{*}\right) \geq \bar{u} \sum_{j=1}^{\infty} \beta^{\prime}\left(1-\delta_{i}\right)^{\prime-1} f_{i}\left(k_{i+s}^{*}\right)
$$

Since liminf $u^{\prime}\left(c_{i}^{*}\right)=\bar{u}$, it follows that for all $\in>0$ there exists $t$ such that $u^{\prime}\left(c_{t}^{*}\right) \leq(1+\epsilon) \bar{u}$. Then, for all such $t$,

$$
1+\epsilon \geq \sum_{s=1}^{\infty} \beta^{\prime}\left(1-\delta_{i}\right)^{s-1} f_{i}\left(k_{i+s}^{*}\right)
$$

Let the right hand side be denoted $d_{i}$, where $d_{i} \leq 1+\epsilon$.

We next show that this inequality contradicts condition $G$. From condition $G$ it follows that there exists $a>0$ such that if $\hat{k}_{i}>0, \beta\left[h_{i}\left(\hat{k}_{i}\right)+1-\delta_{i}\right] \geq 1+a, i=1, \ldots, n$. Let $\in \leq \min _{i} a / 2\left[1-\beta\left(1-\delta_{i}\right)\right]$. Consider the following function $H$

$$
H(k, x)=\sum_{j=1}^{\infty} \beta^{x} f\left[(I-\Lambda)^{j-1} k+\sum_{j=1}^{j-1}(I-\Lambda)^{j} x_{1-1-j}\right]-\sum d_{i} k_{i}
$$

where $k \in \mathbb{R}_{+}^{n}$ and $(I-\Lambda)^{\prime}$ is the diagonal matrix that has elements equal to $\left(1-\delta_{i}\right)^{\prime}$. For any fixed nonnegative sequence $\left(x_{i}\right), H$ is a concave function of $k$ and, given $x_{i}=x_{i}^{*}$, the equality

$$
\sum_{j=1}^{\infty} \beta^{s}\left(1-\delta_{i}\right)^{s-1} f_{i}\left[(I-\Lambda)^{s-1} k_{i}^{*}+\sum_{j=1}^{j-1}(I-\Lambda)^{j} x_{i+j-1-j}^{*}\right]=d_{i}
$$

indicates that it attains a maximum at $k=k_{i}^{*}$. Thus,

$$
H\left(k_{i}^{*}, x^{*}\right) \geq H\left(k, x^{*}\right) \geq H(k, 0) \text { for all } k \in \mathbb{R}_{+}^{n}
$$

Hence, to obtain a contradiction it suffices to show that $H(k, 0)$ cannot attain a maximum. Let $\hat{k}_{m}$ be given by $\dot{k}_{m}=m \cdot \dot{k}$ where $m \in \mathbb{R}_{++}$and $\hat{k}$ is as in condition $G$. It follows that

$$
\hat{H}\left(\hat{k}_{m}, 0\right)=\sum_{j=1}^{\infty} \beta^{s} \sum_{i=1}^{n} h\left((I-\Lambda)^{s-1} \hat{k}_{m}\right)-m \sum_{i=1}^{n} d_{i} \hat{k}_{i} .
$$


Using homogeneity of degree one of $h$ and exchanging summation signs,

$$
\dot{H}\left(\dot{k}_{m}, 0\right)=\sum_{i=1}^{n} \sum_{j=1}^{\infty} \beta^{\prime-i}\left(1-\delta_{i}\right)^{-1} \beta h_{i}(\hat{k}) m \hat{k}_{i}-m \sum_{i=1}^{n} d_{i} \dot{k}_{i}
$$

Given that

$$
\begin{aligned}
\beta h_{i}(\hat{k}) \geq(1+a)-\beta\left(1-\delta_{i}\right) \\
\dot{H}\left(\hat{k}_{m}, 0\right) \geq \sum_{i=1}^{n}(1+a)-\beta\left(1-\delta_{i}\right)\left(\sum_{s=1}^{\infty} \beta^{s-1}\left(1-\delta_{i}\right)^{s-1}\right) m \bar{k}_{i}-m \sum_{i=1}^{n} d_{i} \bar{k}_{i} \\
=m \sum_{i=1}^{n}\left(1+\frac{a}{1-\beta\left(1-\delta_{i}\right)}-d_{i}\right) \hat{k}_{i} \\
\geq m \sum_{i=1}^{n} \frac{a}{2\left[1-\beta\left(1-\delta_{i}\right)\right]} \hat{k}_{i} .
\end{aligned}
$$

Given that not all $\hat{k}_{i}$ 's are zero, $\hat{H}\left(\hat{k}_{m}, 0\right)$ goes to infinity as $m$ goes to infinity. Since for all $k, H(k, 0) \geq \hat{H}(k, 0)$, this implies that $H\left(k_{m}, 0\right)$ goes to infinity as well. This completes the proof of (b).

(a) Under standard Inada conditions it follows that a policy of zero investment (and decreasing consumption) cannot be optimal. Therefore, assume that investment is not zero in some periods. Specifically, let $t$ be the first period such that $x_{t}>0$. Then,

$$
u^{\prime}\left(c_{t-1}\right) \geq u^{\prime}\left(c_{t}\right) \beta\left[f^{\prime}\left(k_{t}\right)+1-\delta\right]
$$

However, given $x_{t-1}=0$, it follows that $c_{t-1}>c_{t}$ and $u^{\prime}\left(c_{t-1}\right)<u^{\prime}\left(c_{t}\right)$. The two inequalities combined imply that

$$
\beta\left[f^{\prime}\left(k_{t}\right)+1-\delta\right]=d<1
$$

Construct, as in the proof of (b), a function $H(k)$ given by

$$
H(k)=\beta[f(k)+1-\delta]-d k
$$

By the previous condition this function has a maximum at $\boldsymbol{k}_{\mathrm{t}}$. Using the same arguments as in the proof of (b), it is possible to show that $H\left(\hat{k}_{m}\right)$ is unbounded, giving rise to the desired contradiction. Note that if $x_{t}>0$, for all $t_{1}$, the Euler equation and condition $G$ show that the sequence $u^{\prime}\left(c_{t}\right)$ is decreasing and, hence, that $c_{t}$ increases monotonically to infinity.

Q.E.D.

The Theorem implies that for the one capital good case it is legitimate to use the Euler equation at equality to characterize optimal paths. 


\section{A Specific Example}

In the rest of the paper we concentrate on tlie one capital good case. Condition $G$ then takes the form $\beta[b+1-\delta]>1$, where $b=\lim _{k \rightarrow \infty} f^{\prime}(k)$. In this section we will explore a specific example of the model outlined above in some detail. Our ain here is to explore the intricacies of the model more completely to see what determines the growth behavior along the optimal path. In section 5 , we will conduct some preliminary analysis of the predicled effects of policy on growth rates.

We will first restrict attention to preferences given when the period utility function, $u$, is of the form $u(c)=c^{1-\sigma} /(1-\sigma), \sigma \geq 0$.

The first question to be addressed is that of existence. As noted above, for this type of utility function existence is guaranteed as long as the maximum feasible growth rate in consumption is less than $(1 / \beta)^{1 / 1-\sigma}$. Clearly this necessitates a joint restriction on $\beta, b$ and $\sigma$, where $b$ is the limiting marginal product of capital. We have:

Proposition 2t Assume that $\beta(b+1-\delta)^{1-\sigma}<1$ and that $u(c)=c^{1-\sigma} /(1-\sigma)$, then an optimal program exists.

Proof: Choose $\epsilon>0$ so that $\beta(b+1-\delta+\epsilon)^{1-n}<1$ and $\hat{k}$ such that $f^{\prime}(k) \leq b+\epsilon$ for $k \geq \hat{k}$. Then by concavity of $f$ it follows that

$$
f(k) \leq f(k)+f^{\prime}(\dot{k})(k-k) \leq f(\dot{k})+(b+c)(k-\dot{k})
$$

for $k \geq k$.

Let $a=f(\hat{k})-(b+c) \dot{k}$ and $\gamma=b+c$. Then, for $k \geq \dot{k}$ we have that output is bounded by

$$
f(k) \leq a+\gamma k
$$

Thus for $k_{0} \geq \hat{k}$ consumption is bounded above by

$$
\begin{gathered}
\bar{\epsilon}_{t}=a+\gamma \bar{E}_{i} \\
E_{t+1}=a+\gamma E_{t}+(1-\delta) E_{t}
\end{gathered}
$$

Because utility is increasing in the initial capital without loss of generality we assume $k_{o} \geq \hat{k}$. It follows that

and

$$
\bar{k}_{1}=(\gamma+1-\delta)^{t}\left[k_{0}+a \sum_{j=1}^{t}(\gamma+1-\delta)^{-j}\right]
$$




$$
\bar{c}_{t}=(\gamma+1-\delta)^{t}\left[\frac{a}{(\gamma+1-\delta)}+\gamma\left(k_{0}+a \sum_{j=1}^{t}(\gamma+1-\delta)^{-j}\right)\right]=(\gamma+1-\delta)^{t} z_{t}
$$

Therefore $u\left(\bar{c}_{t}\right) \leq(\gamma+1-\delta)^{(1-\sigma) t} u\left(z_{t}\right)$, where $u\left(z_{i}\right)$ is bounded. Thus, convergence of

$$
\Sigma \beta^{t} u\left(\bar{c}_{t}\right)
$$

is guaranteed if $\beta(\gamma+1-\delta)^{1-\sigma}<1$ by Proposition 1 .

Note that this proposition taken together wilh Tlleorem 1 can put reasonably tight restrictions on the parameters of the model such that we have both existence and growth. Of course, if $\sigma>1$ and the growth condition is satisfied, Propasition 2 puts on uo restrictions whatsoever.

As far as optimality of sustained growth is concerned, an appeal to Theorem 1 gives the result that growth will occur along the optimal path as long as $\beta(b+1-\delta)>1$. Moreover, an analysis of the Euler equation allows us to say much more given our choice of utility functions.

In this case, the Euler equation gives

$$
c_{i}^{-\sigma}=c_{t+1}^{-\sigma} \beta\left[f^{\prime}\left(k_{t+1}\right)+1-\delta\right]
$$

or

$$
\theta_{1} \equiv c_{t+1} / c_{t}=\left[\beta\left(f^{\prime}\left(k_{t+1}\right)+1-\delta\right)\right]^{1 / \sigma} .
$$

Since $k_{t+1}$ is incressing over time and $f^{\prime}(\infty)=b$. we see two important facts immediately.

First, we see that along the optimal path, growth rates are declining over time $\left(\theta_{2} \geq \theta_{i+1}\right)$.

Second, note that although $\theta_{1}$ decreases. it is bounded away from zero and converges to $\theta^{*} \equiv$ $[\beta(b+1-\delta)]^{1 / \sigma}$. Thus, the model predicts sustained growth with a long-run exponential component.

Note that, quite naturally, this steady-state growth rate is increasing in $\beta$ and $b$, and decreasing in $\delta$ and $\sigma$ (since $\beta(b+1-\delta)>1$ ). Thus, the steady-state growth rate is higher if capital is more productive, the agent is more patient, depreciation is less, or the intertemporal elasticity of substitution is higher. It is interesting to note that although the form of the period utility function does not determine whether or not there is growth, it does determine what the asymptotic rate of growth is.

The exiatence of an ayymptotic growth rate that is consistent with exponential growth is somewhat special. With sufficient curvature in the utility function, it is possible to have consumption growing 
over time at ever decreasing rates, with the asymptotic rate equal to zero. To see this consider the exponential utility function $u(c)=-e^{-\lambda c}$ In this case the relevant Euler equation is

$$
c_{i+1}^{*}-c_{i}^{*}=\lambda^{-i} \ln \left[\beta\left(f^{\prime}\left(k_{i+1}^{*}\right)+1-\delta\right)\right]
$$

It follows that $c_{i+1}^{*}-c_{i}^{*}$ converges to a constant as $k_{i}^{*}$ goes to infinity, with the asymptotic growth rate of consumption equal to zero and the level of consumption going to infinity.

One implication of the one capital good model with fixed labor supply is that capital's share of output approaches one asymptotically. Using condition $G$ it is possible to study multiple capital goods models in which one of the stocks is interpreted as human capital. In that case examples can be constructed such that the share of output corresponding to labor and human capital does not converge to zero. 4

\section{Taxation and Growth}

In this section we will begin our attempt to answer some of the policy questions raised in the introduction. In particular, we will consider the effects on growth rates of various taxes. As we will see, whether or not tax policies affect growth depends on the exact form of the policy, but some indeed do. That is, static distortions of certain types affect not only levels of output but also can have significant impacts on growth rates.

Of course, the difflculty here is that while it is standard that an optimum is equivalent to a competitive equilibrium in models without distortions, this no longer holds (in general) when taxes are introduced.

We concentrate on the study of capital income taxation. To simplify the analysis we will assume that firms do not face dynamic problems. That is, in every period firms rent capital and hire labor in spot markets. Because of the assumption of constant returns to scale, factor payments exhaust output. From the firms maximization problem it follows that each input is paid its marginal product. The rental price of capital, $q_{1}$ is simply $q_{t}=f^{\prime}\left(k_{t}\right)$ while the wage rate is $w_{t}=f\left(k_{t}\right)-k_{t} f^{\prime}\left(k_{t}\right)$.

The representative consumer solves the following problem

$$
\max \sum_{i=0}^{\infty} \beta^{t} u\left(c_{1}\right)
$$

4 One such example is presented in Jones and Manuelli [1988], where it is shown that by choosing the parameters of the model labor share can be any number between zero and one. 
subject to

$c_{t}+x_{t}+r\left(q_{t}-\delta_{+}\right) k_{t} \leq q_{t} k_{t}+w_{t}+T_{t} . \quad t=0.1 \ldots$, with $k_{0}>0$ given.

In writing the budget constraint we have already set the price of capital equal to the price of consumption. Of course this requires that $x_{t}>0$ in equilibrium. If either the relevant version of the condition $\mathrm{G}$ of section 3 is satisfied or the initial capital $k_{0}$ is sufficiently small this is not restrictive. We have also assumed that the tax is levied on the returns of capital net of depreciation costs. It is possible to show that this is equivalent to a $\operatorname{tax}$ on dividends if firms are allowed to deduct depreciation. The depreciation rate, $\delta_{+}$, need not coincide with the "true" depreciation rate 6. We have not allowed the consumer to borrow or lend. This is not restrictive in the framework of a representative agent. Moreover, we call read of the implicit equilibrium interest rate from the first order conditions of the consumer's maximization problem. Finally, the term $T_{t}$ corresponds to transfers received from the government that the consumer considers independent of his behavior. In equilibrium, the requirement of a balanced budget corresponds to $r\left(q_{t}-\delta_{t}\right) k_{t}=T_{t}$. With this condition it will follow that, in equilibrium, $c_{t}+x_{t} \leq f\left(k_{t}\right)$.

To establish the existence of an equilibrium we take an indirect approach. We construct a series of modified economies with no government sector. We then show that the equilibrium prices for one such modified economy can be used to construct the equilibrium prices of the economy with taxes.

We first consider the sequence of economies indexed by $z=\left(z_{t}\right) \quad t=0,1, \ldots$, with planner problems given by:

$$
\begin{aligned}
& \max \sum_{t=0}^{\infty} \beta^{t} u\left(c_{t}\right) \\
& c_{t}+x_{t} \leq \hat{f}\left(k_{t}\right)+z_{t} \\
& k_{t+1}=(1-\delta) k_{t}+x_{t},
\end{aligned}
$$

where $\dot{f}(k)=(1-\tau) f(k)+r \delta_{+} k$.

5 This does not correspond to "accelerated depreciation" (if $\delta_{\mathrm{r}}>\delta$ ) because it does not affect the value of the remaining stock of capital. In this sense, it tends to overstate the effect of an accelerated depreciation scheme. It can be shown that this is equivaleut to the introduction of an investment tax credit such that the household/firm receives a refund of $\delta_{+}$dollars per dollar spent on new capital goods, this will have the same impact on growth as has in this interpretation. 
At this point $\left\{z_{1}\right\}$ should be interpreted as an endow nent secuence. For any sequence $z_{t}$ satisfying $0 \leq z_{t} \leq B_{t}$, where $B_{t}$ is as in Proposition 1. the inodified planner's problem is well defined and the solution is unique due to strict concavity. Denute the optimal sequence of capital by $k_{3}(z)$. We first need to show that there is a sequence $=$ such that a fixed function of $k_{t}(z)$ reproduces the same sequence z. Formally, we have:

Lemma 1z Consider any $z=\left(z_{t}\right)$ such that $z_{t} \in\left[0, B_{t}\right]$ and let $k_{t}(z)$ be the solution to the planner's problem for the modified economy. Let $G(z)_{t}=r\left(f\left(k_{t}(z)\right)-\delta_{r} k_{t}(z)\right)$. Then there exists $z^{*}$ such that $G\left(z^{*}\right)=z^{*}$.

Proof: For any sequence $k=\left(k_{t}\right) \quad t=0,1,2, \ldots$ define $h(k, z)$ by:

$$
h(k, z)=\sum_{t=0}^{\infty} \beta^{t} u\left(j\left(k_{t}\right)+z_{t}+(1-\delta) k_{t}-k_{t+1}\right) .
$$

For any fixed $z$ define the correspondence $\Gamma(z)$ by

$$
\Gamma(z) \equiv\left\{\left(k_{t}\right) \text { such that } k_{t+1} \geq(1-\delta) k_{1} \text { and } k_{t+1} \leq j\left(k_{t}\right)+(1-\delta) k_{t}+z_{t}\right\}
$$

Finally, define the space $Y=\prod_{t=0}^{\infty}\left[0 . B_{i}\right]$. where $B_{t}$ is an upper bound for any feasible capital stock sequence. For example, $B_{t}=f\left(\bar{k}_{t}\right)$ witl $\bar{k}_{t+1}=f\left(\bar{R}_{t}\right)+(1-\delta) F_{1}$ satisfies the assumptions. The set $Y$ is compact in the product topology. The correspondeuce $G(z)$ is continuous and, for each $z$, a closed subset of $Y$ and, consequently, compact. Moreover, given zeY all ke $\Gamma(z)$ also belong to $Y$. The social planner's problem for the modified economy can be described as:

$$
\max h(k, z) \text {. }
$$

$k e \Gamma(z)$

By the Theorem of the Maximum the set of maximizers is an upper hemicontinuous correspondeace of $z$. Because the objective function is strictly concave, this set is a siogleton and the maximizer, $\left\{k_{t}(z)\right\}$, is a contiouous function of $z$. By construction, the mapping $G$ is a continuous function of $k$ and, consequently, of $z$. G maps the compact, convex set $Y$ into itself and, thus, it has a fixed point $z^{*}$

Q.E.D.

If we index modified economies by sequences $z$, it is standard to use the results from Debreu [1954] to show existence of a competitive equilibrium. Moreover, the results of Prescott and Mehra [1980] show that we can support the same allocation by just looking at a sequence of markets for capital and labor. If the solution is interior the prices should be given by

$$
\dot{q}_{t}(z)=\dot{f}^{\prime}\left(k_{t}(z)\right)=(1-\tau) f^{\prime}\left(k_{t}(z)\right)+\tau \delta_{\tau}
$$




$$
\dot{w}_{t}(z)=f\left(k_{1}(:)\right)-k_{t}(z) f^{\prime}\left(k_{t}(z)\right)
$$

Note also that, at the fixed point $z^{*}$, the feasibility constraint for both the original and the modified economy coincide. That is $\dot{f}\left(k_{t}\left(z^{*}\right)\right)+z_{i}=f\left(k_{t}\left(z^{*}\right)\right)$.

We are now ready to establish existence of all equilibrium.

Theorem 2: Assume that the existence conditions of section 9 are satisfied. There exists an equilibrium for the economy with distortionary taxes. The equilibrium prices are given by $q_{t}^{*}=$ $f^{\prime}\left(k_{t}\left(z^{*}\right)\right)$ and $w_{i}^{*}=f\left(k_{t}\left(z^{*}\right)\right)-k_{t}\left(z^{*}\right) f^{\prime}\left(k_{t}\left(z^{*}\right)\right)$, and the equilibrium allocation corresponds to that of the planner's allocation for the modified economy when $z=z^{*}$.

Prooff For $z=z^{*}$ the planner's allocation solves the representative consumer's competitive problem

$$
\begin{aligned}
& \max \sum_{i=0}^{\infty} \beta^{f} u\left(c_{t}\right) \\
& \text { subject to } \\
& c_{t}+x_{t} \leq \dot{q}_{t}\left(z^{-}\right) k_{t}+w_{t}\left(z^{-}\right)+z_{i} \\
& k_{t+1}=(1-\delta) k_{t}+x_{t}
\end{aligned}
$$

By definition of $q_{i}^{*}$ and $w_{i}^{*}$ and letting $T_{i}^{*}=\left(q_{i}^{*}-\delta_{r}\right) k_{t}\left(z^{*}\right)$, we have that $\hat{q}_{\mathrm{t}}\left(z^{*}\right) k_{i}+\dot{w}_{t}\left(z^{*}\right)+z_{i}^{*} \equiv$ $(1-\tau) q_{i}^{*} k_{t}+\tau \delta_{r} k_{t}+w_{i}^{*}+T_{i}^{*}$, where the equality holds identically in $k_{i}$. Given that the right hand side determines the budget constraint for the representative consumer in the original economy, it follows that the two budget constraints are identical. If $c_{t}\left(z^{*}\right), x_{t}\left(z^{*}\right), k_{t}\left(z^{*}\right)$ is the solution to the competitive problem faced by the representative consumer in the modified economy when $z=z^{*}$, it must also solve the equivalent problem for the consumer in the original economy. The firm's problem, being static, is automatically satisfied by our choice of prices.

To characterize the equilibrium with distortions we use the first order conditions for the modified planner's problem at $z=z^{*}$. The Euler equation (that always holds if $k_{0}$ is sufficiently small) is:

$$
u^{\prime}\left(c_{i}^{*}\right)=u^{\prime}\left(c_{i+1}^{*}\right) \beta\left[f^{\prime}\left(k_{i+1}^{*}\right)+1-\delta+\tau\left(\delta_{7}-f^{\prime}\left(k_{i+1}^{*}\right)\right)\right] .
$$

Notice that if $\delta_{\mathrm{T}}<f^{\prime}(k)$ for all $k$, the asymplotic growth rate of the marginal utility is given by $\max \left[1, \beta\left(b+1-\delta+\tau\left(\delta_{T}-\delta\right)\right)\right]$.

It follows that if $\delta_{7}=\delta$ and if $\tau$ is sufficiently large the economy will converge to a steady state. In general, positive $r$ 's will result in a decrease in the asymptotic growth rate relative to the no 
tax situation. The case $\delta,=6$ results in an asymptotic growth rate that is similar to the no tax situation. This case corresponds to a situation in which all the additional income generated by capital $(b)$ is not taxed because it is considered equal to depreciation $\left(\delta_{+}\right)$.

The case $\beta(b+1-\delta+r(\delta,-b))<1$ is interesting to illustrate the difference between "growth" and "level" effects. In this case the economy reaches a steady state with the steady state capital stock satisfying

$$
\beta\left[f^{\prime}\left(k_{r}\right)+1-\delta+\tau\left(\delta_{r}-f^{\prime}\left(k_{r}\right)\right)\right]=1
$$

Where $k$, indicates the steady state capital stock when the tax rate is $r$.

If, atarting at the steady state, the tax rate is lowered while still keeping the expression for the discounted marginal return less than one, the impact of this change is to generate growth until the economy reaches a higher steady state. In this case changing $\tau$ only has level effects.

If, on the other hand, $3\left[\left(b+1-\delta+r\left(\delta_{r}-b\right)\right)\right\}>1$. a decrease in $r$ has the effect of increasing the asymptotic growth rate of the marginal utility. It then follows that changes in taxation may have level or growth effects depending on the importance of the initial distortion.

To summarize this discussion we have

Proposition 3: Proportional tares on capital income can affect both whether sustained growth will occur in equilibrixm and its asymptotic level. In particular, the imposition of such a tax could move the economy from the region of sustained equilibrium growth to one where there is no growth in the long run along the equilibrism path.

We must point out that to emphasize the impact of capital income taxation we have assumed constant marginal tax rates. Our approach to existence is robust to tax rates that depend on both aggregate capital stock and that vary over time.

On the other hand, our description of the tax code was kept very simple to emphasize the role of capital income taxation on growth. Due to the convexity of the problem it is possible to analyze more complex tax policies as in Brock and Turnovslyy [1981], and Judd [1985], [1986], [1987]. This paper is complementary to those studies in the sense that it provides an existence result that extends to arbitrary time varying tax rate. A similar approach can be used to study differential taxes on specific forms of capital as well as labor income.

Finally, it is possible to obtain the same qualitative results if instead of taxing capital income, the government levies a tax on nonhuman wealth. In this case Becker [1985] has shown that the 
competitive equilibrium allocation is the solution to a planner's problem. In this case, the problem being solved has the lower discount factor, $\beta(1-\tau)$. Our analysis of section 3 applies directly, and it follows that taxation may reduce the asymptotic growth rate even to the point of causing the economy to converge to a steady state.

\section{Growth and International Trade}

To this point, the results, although suggestive, do uot really answer the questions put forth in the introduction. That is, although we have slown that government policies can impact growth rates in nontrivial ways (if they affect intertemporal nuargins), this has been in a closed-economy setting. Our goal in this and succeeding sections is to begin to analyze these questions in a world with international trade. To accomplish this we will heyin by considering the simplest generalization of the economy analyzed to this point which admits imerpretation as being with many countries.

Consider an economy with two consumers with utility functions given by

$$
U_{i}(c)=\sum_{i=0}^{\infty} \beta_{i}^{t} u_{i}\left(c_{i}^{j}\right), \quad i=1,2
$$

They are endowed with labor $\ell_{t}=1$ for all $i$ and $t$ and initial capital stocks $k_{0}^{2}$ and $k_{0}^{z}$. We will assume that the two individuals "live" in distinct locations. Formally, there are two types of consumption goods, two types of investment goods, and two types of labor. In what follows, we will assume that the consumption and investment goods are freely substitutable while labor is not (i.e., transportation costs are zero for consumption and investment goods and infinite for labor). Thus, a country is defined by the lack of labor mobility.

In each country there is one firm with production function given by $y_{t}^{i}=F^{i}\left(k_{t}, \xi_{i}\right), i=1,2$. As above, we will assume that $F$ is homogetieous of degree one and define $b_{i}=\lim _{K} \rightarrow \infty \partial F^{i}(k, 1) / \partial k$. Again, labor is assumed to be inelastically supplied.

We consider a setting in which country one taxes the return on capital in place irrespective of ownership, that in, country two's residents have to pay country one's taxes if they rent capital to firms in country one. Country two imposes no taxes, but residents of country one are taxed by their own government on the income generated by their capital which they rent to firms in country two.

Free trade guarantees that the price of consumption and investment goods is equal in both countries. In this simple setting there is only one good that can be traded; capital. The reason for this is simple: differences in (after tax) rates of return generate offsetting capital fows. The bey price that determines the allocation of world resources is the rate of return in each country. 
In order to make our point that differences in country policies can induce differences in long run growth even in the absence of any barriers to trade, it is sufficient to show that autarky is an equilibrium. If this is the case the analysis of the previous section shows that country one's growth rate is lower.

In Proposition 4 we formalize this idea.

Proposition 4: Let the tax on capital income in country one be $r$ and assume $\delta_{r}=\delta$. Assume $u_{i}^{\prime}(0)=\infty$ and $b_{1}=b_{3}=b>0, \beta_{1}[(1-\tau)(b-\delta)+1]>1$ and $\beta_{2}[b-\delta+1]>1$ and that the existence conditions are satisfied country by country. Then,

(a) If $f^{\prime}(k)=f^{2}(k), \beta_{1}=\beta_{3}$ and $u_{1}=u_{3}$, there exists $k^{*}$ such that if $k_{0}^{2} \geq k_{0}^{1} \geq k^{*}$, the free trade equilibrium allocation corresponds to autarky.

(b) If $f^{1}(k)=f^{2}(k)=b k$, then the equilibriun allocation is autarky, independent of initial conditions.

Proof: The proof strategy is simple: compute the autarkic allocation for each country and then show that residents of country one do not want to invest in country two and vice versa.

Let $\left(c_{i}^{i}, k_{t}^{i}, x_{i}^{i}\right)$ be the solution to country $i^{\prime} s$ planuing problem (a modified planning problem for country one) and let the gross before tax rate of return be given by

$$
1+r_{i t}=f^{\prime}\left(k_{i}^{i}\right)+1-\delta \quad i=1,2 \text {. }
$$

This simply reffects a standard arbitrage condition that equalizes the rates of return within a country between holding real and financial capital.

(a) Proposition A.1 in the appendix shows that $k_{i}^{2} \geq k_{\mathrm{f}}^{1}$ for all $t$. Thus the after tax rates of return faced by residents of country one are given by

$$
(1-\tau)\left[f^{\prime}\left(k_{i}^{1}\right)-\delta\right]+1 \text { and }(1-\tau)\left[f^{\prime}\left(k_{i}^{2}\right)-\delta\right]+1 .
$$

Therefore, given concavity of $f_{,} f^{\prime}\left(k_{t}^{+}\right) \geq f^{\prime}\left(k_{t}^{2}\right)$ and residents of country one will never choose to invest in country two.

To complete the proof we need to show that residents of country two will choose not to invest in country one. This will be the case if and only if

$$
f^{\prime}\left(k_{t}^{2}\right)+1-\delta \geq(1-r)\left[f^{\prime}\left(k_{t}^{1}\right)-\delta\right]+1
$$


Note that the left side converges to $b+1-\delta$ and hence for $k^{*}$ large we have

$$
b+1-\delta \geq(1-\tau)\left[f^{\prime}\left(k^{*}\right)-\delta\right]+1
$$

Because the capital stock in each country increases, if $k_{0}^{1} \geq k^{*}$ the rate of return in country one is bounded above by $(1-\tau)\left[f^{\prime}\left(k^{*}\right)-\delta\right]+l$ and country two's residents do not invest in country one. This completes the argument.

(b) The argument is similat to (a) with $f^{\prime}(k)$ replaced by b everywhere. As $f^{\prime}(k)$ is independent of $k$, initial conditions play no role in this case.

Q.E.D.

There are several things to note about this result.

First, as promised, under the stated conditions. we are able to give a very precise characterization of the competitive equilibrium with taxes-it is antarky. This will allow us to make very strong statements about the effects of taxes on growth below (in country 1 ).

Second, note that in the absence of government distortions. autarky is not a competitive equilibrium. In case (a), countries trade to equalize rates of return on capital if $k_{0}^{2}>k_{0}^{1}$. In case (b), there is trade due to differences in discount rates and utility functions (rates of return are automatically equalized here due to the special form of the production function). Thus, it is immediate that the government policies have effects since they move us from an equilibrium with trade to one without. What is missing still is that the effects are on growth rates (i.e., not just on levels).

Third, note that we have assumed that physical capital is perfectly mobile in our formulation. It is straightforward to check that the result remains true in a world in which investment goods are perfectly mobile but physical capital in place cannot be moved so long as consumers initial endowments of capital at time zero were located entirely in the "home" country.

Fourth, note that we have continually remornalized pricts so that consunption costs one (unit of account). Alternatively, one could normalize all prices in teams of time zero consumption goods. It is straightforward to check that the proof given will not work in this case. This is nothing but the standard difficulty in determining what constitutes investment income (or saving) in a world with forward contracts. Basically, the problem is that autarky gives rise to different time paths of prices in the two countries so that consumers in the high price country would not want to buy their own output. In this case, one can still get the conclusion of the proposition by, in addition to having taxes on capital, introducing tariffs on imports. With the appropriate choice of tarifts, autarky will again be the equilibrium and the basic conclusion (that policies have growth effects) will still be valid. This is, of course, the nonrecursive analog of our assumption about taxation of capital income. 
Fifth, note that the only way we used our assumptions that $u_{1}=u_{2}$ and $\beta_{1}=\beta_{2}$ in the proof of part (a) was to guarantee that $k_{t}^{2} \geq k_{t}^{1}$ for all $t$. Alternatively, one could obtain the same result by having country 1 tax foreign investments at a different (higher) rate than domestic ones.

Finally, note that the analog of our Proposition 3 generalizes in this case as well.

Proposition 5: Assume that $j_{1}[(1-\tau)(b-\delta)+1]<1$, that $j_{2}(b+1-\delta)>1$, that the assumptions for eristence are satisfied country by country and that $f^{1}=f^{2}$. Then, if $u_{1}=u_{2}$, there is a $k^{\cdot}$ such that if $k_{0}^{2} \geq k_{0}^{1} \geq k^{*}$, the equilibrium is autarky.

Proof: Choose $k^{*}$ so that $\beta_{1}\left[(1-\tau)\left(f^{\prime}\left(k^{*}\right)-\delta\right)+1\right]=1$. It is a standard argument to show that the autarkical values of $k$ in country 1 converge monotonically to $k^{*}$. Given this, the arguments of Proposition 4 can be used to show that the rates of return in the taxed country are never high enough to justify investment there by residents of the untaxed country.

Q.E.D.

We turn now to the question of characterizing the social optima in our two country world.

Proposition 6: Assume that $\beta_{i}(b+1-\delta)>1, i=1,2$, and that the other assumptions of Theorem $I$ are satisfied. Then, in any social optimum (with positive weights on both individuals) consumption of the $i$-th individual satisfies

$$
u_{i}^{\prime}\left(c_{i}^{i}\right)=\beta_{i} u_{i}^{\prime}\left(c_{t+1}^{i}\right)\left\{f^{\prime}\left(k_{i+1}\right)+1-\delta\right\} \quad i=1,2
$$

where $k_{t+1}=(1 / 2)\left(k_{t}^{1}+k_{t}^{2}\right)$.

Proof: Consider the problem of maximizing

$$
\sum_{t=0}^{\infty}\left[\alpha_{1} \beta_{1}^{t} u_{1}\left(c_{t}^{1}\right)+\alpha_{2} \beta_{3}^{1} u_{3}\left(c_{t}^{2}\right)\right] .
$$

subject to the obvious technological constraints. It is immediate that optimality requires equal split of the capital stock across the two countries.

Further, it is straight forward to show that at the optimum

$$
\alpha_{1} \beta_{1}^{\prime} u_{1}^{\prime}\left(c_{1}^{1}\right)=\alpha_{2} \beta_{2}^{\prime} u_{2}^{\prime}\left(c_{2}^{2}\right)
$$

Finaliy, note that the results of section 3 can be generalized to show that the Euler equation holds in this case. Thus it follows that

$$
\alpha_{1} \beta_{1}^{\prime} u_{1}^{\prime}\left(c_{t}^{l}\right)+\alpha_{2} \beta_{2}^{\prime} u_{2}^{\prime}\left(c_{1}^{2}\right)=\left[\alpha_{1} \beta_{1}^{t+1} u_{1}^{\prime}\left(c_{i+1}^{2}\right)+\alpha_{2} \beta_{2}^{t+1} u_{2}^{\prime}\left(c_{t+1}^{2}\right)\right]\left[f^{\prime}\left(k_{i+1}\right)+1-\delta\right] .
$$


Substitution and simplification give the desired result.

Taken together, Propositions 4, 5, and 6 allow us to make simple direct comparisons about growth rates of consumption in country 1 with aud willout distortions. In particular, the results allow us to conclude that the difference between growth rates in the tax and no-tax competitive equilibrium in country 1 correspond to a reduction in the marginal product of capital from $f^{\prime}(k)-\delta+1$ to $(1-\tau)\left(f^{\prime}(k)-\delta\right)+1$. In particular, with preferences of the form $u_{i}(c)=c^{1-\sigma i} /\left(1-\sigma_{i}\right)$, the asymptotic grow th rate of consumption is lower with taxes than without in an international setting. Moreover, if $\beta_{1}=\beta_{2}$ consumption grows at a slower rate in country 1 than in country 2 . Similarly, under the conditions of Proposition 5, it follows that if $\beta_{1}(b+1-\delta)>1$ and $\beta_{1}((1-\tau)(b-\delta)+1)<1$, the competitive equilibrium without taxes has growth in both countries while that with taxes has growth only in country 2.

As a final comment, note that Proposition 6 sliows that the results of Becker [1980] concerning the asymptotic distribution of consumption whell $\beta_{1}$ and $\beta_{2}$ are different do not generalize to a growth setting. In particular, although it follows (from the fact that $\alpha_{1} \beta_{1}^{t} u_{1}^{\prime}\left(c_{1}^{1}\right)=\alpha_{2} \beta_{2}^{z} u_{2}^{\prime}\left(c_{t}^{2}\right)$ ) that the ratio of marginal utilities goes to zero, this implies that the consumption of one agent goes to zero only if aggregate consumption is bounded. In our case, the ratio of consumption goes to zero while both grow without bound.

\section{Growth with Tarifts}

In this section we begin to explore some of the implications of the model for the analysis of trade policy and of policies that tax international flows of capital. We need to modify the basic one good model in order to explore the effects of import tarifts. The simplest way of doing this is to consider a Ricardian model of trade in which differences between the home and the foreign country are due to different technologies.

We will show that, depending on other restrictions, changes in trade policy may have permanent effects (effects upon the asymptotic growth rates) or just temporary effects (effects on the level but not the growth rate of the economy).

We modify the basic model of Section 3 to allow for a different marginal rate of transformation between investment and consumption. The technology is given by

$$
\begin{aligned}
& c_{t}+a x_{t} \leq f\left(k_{t}\right), \\
& k_{t+1}=(1-\delta) k_{t}+x_{t}, \\
& \left(c_{t}, x_{1}\right) \geq 0, a \geq 1 .
\end{aligned}
$$


To describe the path of this economy in autarky we can follow the same argument as in Section 3. it is a straightforward extension to show that the relevant "growth condition" is $\beta[(b / \alpha+1-\delta]>1$. It then follows that if the country is sufficiently inefficient in the production of investment goods ( $\alpha$ is sufficiently large), the competitive equilibrium will converge to a steady state. Specifically, an argument similar to Proposition 3 shows that if $\beta[b / \alpha+1-\delta]<1$, output converges to a steady state, with the steady state capital stock $k^{*}$ given by the solution to $\beta\left[f^{\prime}\left(k^{*}\right) / \alpha+1-\delta\right]=1$. In general, the higher the value of $\alpha$ the lower the asymptotic growth rate and the welfare of the representative agent. (It is simple enough to consider the case where the technology is given by $\alpha_{1} c_{t}+\alpha_{2} x_{t} \leq f\left(k_{t}\right)$, for $\left(\alpha_{1}, \alpha_{2}\right) \geq 1$. In this case the size of $\alpha_{1}$ does not affect the asymptotic growth rate, although it does reduce welfare. Basically, to affect growth rates we need to distort the marginal rate of substitution between consumption at different dates. while an inefficiency in the consumption sector simply makes consumption equally more expensive in every period.)

For simplicity we assume that the rest of the world has $\alpha=1$. As in any Ricardian model, under free trade there is specialization. The home country produces only consumption and it imports investment. If the initial capital stocks are the same for all countries, there is no international borrowing and lending and the trade balance is zero in every period. Note that even in a world in which all countries have access to the same technology, there could be international trade if initial capital stocks were different. This, of course, corresponds to the equilibrium of a closed economy with heterogeneous agents that we studied in section 6 . Our results about asymptotic growth rates remain unchanged but trade is in general not balanced.

If we assume $\beta[(b / \alpha)+1-\delta]>1$ our argument is Section 3 shows that the international price of the investment good relative to the consuniption good is one. Suppose that the home country prohibits international borrowing and lending and that it imposes a tariff on imports of investment equal to $\tau_{x}$. That is, if investment goods are purchased abroad, their domestic price (in terms of consumption) is $1+\tau_{x}$.

Without going over the details of the argument, it is easy to see that if $1+T_{x}>\alpha$ the equilibrium is autarky. This is because it is more expensive to purchase the good abroad than to produce it domestically. The asymptotic growth rate of marginal utility of consumption is, simply, $\beta[(b / \alpha)+$ $1-\delta]$.

Keeping the assumption that there is an infinite tax on international borrowing and lending, assume that the import tariff is lowered so that $1+\tau_{x}<\alpha$. The representative household solves the following problem: 
$\max \Sigma \beta^{t} u\left(c_{t}\right)$

s.t. $c_{t}+p_{t} x_{t} \leq w_{t}+q_{t} k_{t}+T_{t}$

$$
k_{t+t}=(1-\delta) k_{t}+x_{t}
$$

where $p_{t}$ is the relative price of investment, $q_{t}$ the rental price of capital, $w_{t}$ the wage rate, and $T_{t}$ a transfer from the government. Of course, although the household views the transfer as independent of its own actions, in equilibrium we must have $\tau_{t} x_{t}=T_{t}$, i.e., the government has a balanced budget.

If $x_{l}>0$, we must have $p_{t}=1+\tau_{z}$. It is possible to show that the equilibrium allocation solves a modified planner's problem (in essence the argument is similar to the one used to establish the existence of equilibrium with distortionary taxes), that $x_{l}>0$, and that the first order conditions are given by

$$
u^{\prime}\left(c_{t}\right)=J u^{\prime}\left(c_{i+1}\right)\left\{f^{\prime}\left(k_{i+1}\right) /\left(1+r_{2}\right)+1-\delta\right\}
$$

In this case the asymptotic growth rate of the ratio of marginal utility is $\beta\left[b /\left(1+T_{x}\right)+1-\delta\right]$ which is greater than $\beta[(b / \alpha)+1-\delta]$. Therefore, in this case, trade liberalization has "growth effects."

Consider next an economy where international capital flows, although not prohibited, are subject to a $\operatorname{tax} \tau_{k}$. Specifically, let $L_{t}$ be the amount lent by the home country to the rest of the world. If $\left(1+r_{t}\right)$ is the world interest rate, the representative agent faces the following decision problem:

$\max \Sigma \beta^{t} u\left(c_{t}\right)$

s.t. $\quad c_{t}+p_{t} x_{t}+L_{t} \leq w_{t}+q_{t} k_{t}+\left[1+r_{t}\left(1-T_{t}\right)\right] L_{t-1}+T_{t}$ $\left(L_{1}, c_{t}, x_{1}\right) \geq 0$.

The interpretation is simple: households have to pay the government a tax of $r_{k}$ per dollar of interest received. In equilibrium, we must have $\tau_{z} x_{t}+\tau_{k} r_{t} L_{t}=T_{t}$.

Notice that, as stated, residents of the domestic country can lend to the rest of the world but cannot borrow from it. This assumption simplifies the analysis of the recursive problem. As it is well known, if borrowing is allowed we need to supplenest the standard sequence of budget constraints so as to prevent individuals from borrowing infinite anounts. In the version with borrowing allowed, and if domestic residents have to pay a tax on international borrowing, it must be the case that, for large $k_{1}$ the rate of return on domestic investment is less than the rate at which households borrow. Therefore, at least for large $k$, the optimal amount of borrowing is zero.

Formally, the decision problem faced by the household is how to allocate investment to the two possible intertemporal technologies: the domestic technology that has rate of return equal to 
$\left(f^{\prime}(k) /\left(1+r_{x}\right)+1-\delta\right)$, and the international technology tlaat has $1+r\left(1-r_{k}\right)$ as its rate of return. We assume $3\left[1+r\left(1-\tau_{k}\right)\right]>1$. For this problem it is possible to show that the equilibrium allocation is the solution to a modified planner's problem. To map this economy into that of section 5. notice that this is an economy that has two technologies for capital accumulation: the standard technology given by $f$ and another linear teclunology given by $1+r\left(1-\tau_{k}\right)$.

Consider first the case $b /\left(1+\tau_{x}\right)+1-\delta>1+r\left(1-T_{k}\right)$. This says that the domestic technology dominates, and that the optimal solution simply has $L_{t}=U$ for all $t$. Of course, the asymptotic growth rate of the marginal utility is given by $s\left[b /\left(1+\tau_{x}\right)+1-\delta\right]$. Consider a policy that lowers $r_{k}$ but that still leaves the doinestic rate of return higher than the after tax rate of return in the international market. This change will have no effects upon the equilibrium decisions. In this case decreasing taxation of capital flows has no inpact while a decrease in $\tau_{x}$ has, as we argued before, "grow th" effects.

However, the case $b /\left(1+\tau_{x}\right)+1-\delta<1+\tau\left(1-\tau_{k}\right)$ is different. In this case the domestic technology is eventually dominated. A standard no rate of return dominance argument establishes that domestic output will never exceed $f\left(k^{L}\right)$ where $k^{L}$ solves:

$$
f^{\prime}\left(k^{L}\right) /\left(1+\tau_{x}\right)+1-\delta=1+r\left(1-\tau_{k}\right)
$$

Because we assume $\beta\left(1+r\left(1-T_{k}\right)\right)>1$, we can argue that consumption must be increasing at a faster rate than in the case of portfolio autarky. Output, however, remains bounded. In this economy households save in international markets and use the proceeds to finance an ever increasing level of consumption.

In this case, trade policy can have only "level" effects. Cousider two countries that are identical except for import tarifts; let $\tau_{x}^{1}<\tau_{x}^{2}$. Moreover, assume that

$$
b /\left(1+\tau_{x}^{1}\right)+1-\delta<1+r\left(1-\tau_{k}\right)
$$

The argument we used above shows that output will eventually converge to $f\left(k_{i}^{L}\right)$ where $k_{i}^{L}$ solves

$$
f^{\prime}\left(k_{i}^{L}\right) /\left(1+\tau_{x}^{i}\right)+1-\delta=1+r\left(1-\tau_{k}\right)
$$

Clearly $k_{1}^{f}>k_{2}^{L}$, and a decrease in $\tau_{x}$ can temporarily increase output but it will eventually level off at a higher value. (We have not shown convergence but equilibrium for each economy solves a "modified" planner's problem. We call then use the methods of Section 3 to establish convergence.) 
It is also interesting to study the impact of a decrease in $r_{k}$. Specifically, let $r_{k}^{1}<r_{k}^{2}$ and assume that $b /\left(1+\tau_{x}\right)+1-\delta<1+r\left(1-\tau_{k}^{l}\right)$. Consider a country that has a tax equal to $\tau_{k}^{2}$ and has reached a steady state le vel of output $f\left(k_{2}\right)$, where $k_{2}$ solves the obvious equality of rates of return equation. If the tax is lowered to $\tau_{k}^{1}$, this will imply that the new steady state must have $f\left(k_{1}\right)<f\left(k_{2}\right)$ (the new steady state has a higher rate of return). and this is accomplished by reducing domestic investment and increasing savings in international markets. Thio behavior would look like a classic instance of "capital fight" triggered by the lowering of the bartiers to capital flows. Of course, this change will also result in a higher growtl rate of consuuption und higher welfare. In this instance capital flight is beneficial because it corresponds to a shift in the composition of national savings towards a larger share of it invested in the "foreign technology" that has improved.

Although in the model it is clear what we mean by taxation of capital fows, it is not obvious how such a policy can be implemented. In particular, what prevents individuals from exporting and importing the consumption good (that has a zero tariff) in such a way as to mimic the intertemporal fow of income generated by borrowing and lending? The simple answer is that nothing prevents them from getting around the system in the context of the model. In the real world, however, exchange controls can serve as an effective way of enforcing the policy. Whether they are enough to replicate our setup is a question that deserves further attention.

We think that this exercise is valuable. It shows that in a very simple model with a trivial laissez faire equilibrium the effects of removing distortions one at a time are not obvious. The growth or level effects of a change in trade policy or barriers to capital mobility depend on the levels of the other policies. There is a sense in which it indicates that one must "look at everything" before reaching policy conclusions and it highlights the nol so obvious interrelations between trade regimes and international capital fows. It indicates that "comprehensive" studies of policy changes (Krueger [1978], [1986] and Corbo, et. al [1985]) are more appropriate than sharply focussed investigations that ignore the policy package in place.

\section{Concluding Comments}

To finalize the paper we offer some comments on the results, related literature, and future research.

1) Our goal in this paper has been to develop and analyze a model in which the growth rate of output and consumption are both positive and endogenous. In so doing, we have implicitly provided answers to the questions rajsed in the introduction.

The analysis implies that principal determinants of growth rates include both economic fundamentals (parameters of tastes and technology) and government policy variables. In particular, because 
of the relatively simple structure of the key equation to understand growth, the model suggests concentrating on the factors affecting the rate of retur.l on investment. Besides the obvious preference and technological parameters. it indicates that government policies that affect the rate of return on capital have an impact on growth.

It is tempting to attribute the bulk of recent differences in growth histories between countries (e.g., Korea and Japan versus the U.S.) to differences in tastes (i.e., betas) rather than differences in policies. Although this is in principle consistent with the model, the difficulty with this view is in rationalizing the apparent changes in growth rates across time in a given country (e.g., Korea pre and post 1959 -see Krueger [1986]).

For this reason, it is compelling to concentrate on government policies as the primary explanation for differences in growth. In this regard, it is of interest to interpret the recent work of Makin and Shoven [1987]. Their study indicates thal marginal incone from capital is taxed at much higher rates in the U.S. than in Japan. Within the context of the model, this is perfectly consistent with identical tastes in the two countries and the observed growth patterns. (See comments 4 and 5 below concerning the welfare effects of different growth rates.)

2) The presence of increasing returns to scale is neither necessary nor sufficient to generate sustained growth. That it is not necessary follows from the arguments of section 3. That it is not sufficient follows from the conditions imposed by Romer [1986] or, more directly by considering the following technology $F(k, \ell)=k^{\alpha_{1}} \ell^{\alpha_{1}}$ with $\alpha_{1}+\alpha_{2}>1$ and $0<\alpha_{1}<1$. The arguments of section 3 can be applied to show that for this economy sustained growtin is not feasible. Similarly, the existence of growth does not depend on exact linearity, the lack of fixed factors or the specific form of the utility function. The crucial feature to attain sustained growth seems to be that the marginal product of capital remain bounded away from zero. Whether this is generated by a convex technology or not is not easential. In the example of increasing returns we need $\alpha_{1} \geq 1$ to guarantee that this marginal product remains bounded away from zero.

3) The model is a useful vehicte for discussiug whether specific policies have "level" or "growth" effects. This, however, should not be read as inplying that policies that have growth effects have a larger impact upon the representative agent utility. The reason for this is that our existence condition essentially implies that growth has a small impact upon utility. For utility to be defined, it is necessary that the growth rate of instantaneous utility does not exceed $1 / \beta$. Therefore, the importance of consumption growth is bounded. Put differently, the model is continuous in all parameters including policy parameters. We have shown that small changes can result in movements 
from sustained growth to a region where there is a steady state. By continuity, these small changes cannot have large effects on the utility of the representative agent.

4) Given the convex structure of our model and the lack of externalities, the competitive equilibrium is Pareto optimal. Therefore, the model gives too sinple an answer to the question of which is the optimal policy. It is simply laissez faire. In models with increasing returns/externalities it may well be the case that some of the policies that we find distortionary are optimal. For example, in the presence of externalities generated by the stock of capital, it is likely that the optimal policy requires subsidizing investment. In the model of this paper this policy will also increase the growth rate to a suboptimal (too high) level. See comment 5 .

5) It is fairly simple to show that some policies may generate too much growth. Consider, for example, the capital income taxation problem of section 6 . The two instruments that the government has are the tax rate $\tau$ and the depreciatioll allowance $\delta_{r}$. If $\delta_{r}>b$ (of course this requires $\delta_{r}>\delta$ ), the asymptotic growth rate of the marginal utility is higher than in laissez faire. In this case, for large $k$ the government's transfer to the representative household is negative; that is, the government uses lump-sum taxes to subsidize the returns to capital. Another more realistic fiscal policy is to tax consumption and to use the proceeds to subsidize purchases of the investment good. In this case the tax on consumption acts as a lump-sum tax. (The only taxes of consequence in this model are those that change the relative prices of the different consumption goods; a uniform tax on consumption does not affect the marginal rate of substitution between consumption at different dates and, hence, it is neutral.) $)^{6}$ The decrease in the effective price of investment (the after tax price) raises the rate of return on capital, increases investment and, consequently, growth. In the context of our model, policies that artificially increase the growth rate are detrimental to welfare.

6) The next step in this research program is to incorporate a realistic pattern of productivity shocks to the model, as was done by Brock and Mirman [1972] for the standard one sector model. (We can consider shocks that can take on a finite number of possible values within our framework without any changes.) Allowing for variable labor supply will allow us to study a model that generates both fluctuations and growth. In such a model we will not need to make any special assumptions about detrending. This is particularly important because in its current nonstochastic version the model does not predict that, asymptotically, all relevant variables will grow at the same rate. A specific

6 In a version in which the supply of labor is elastic the consumption tax is distortionary: it affects the trade off between consumption and leisure. Depending on preferences, the intertemporal decision may not change, resulting in no effects on growth rates. 
example is the laissez faire version of our two country world when the discount factors are different. In that case output grows at the same rate in both countries but aggregate consumption does not. At a general level we cannot rule out differential growt hates and therefore the possibility that most detrending procedures are not appropriate.

The second reason why we thitik this extension is illteresting is because it will allow us to evaluate macroeconomic policies in terms of their "full" effects; that is both in terms of their stabilization and their growth effects. Current nodels that abstract from the possibility of sustained growth must of necessity concentrate on only one dimension.

Additionally, the role of taxation in multigood multicapital economies needs to be explored. Our analysis shows that when there is more than one capital good (this is the case in our study of the open economy) the details of the tax code and other distortions are crucial to understand the long run effects. 


\section{References}

Arrow, Kenneth J. "The Economic Implicatious of Learning by Doing." Rev. Econ. Studies 29 (June 1962): 155-73.

Becker, Robert. "On the Long-run Steady State in a Sinple Dynamic Model of Equilibrium with Heterogeneous Households." Q.J.E. 95 (September 1980): 375-82.

Becker, Robert. "Capital Income Taxation and Perfect Foresight." J. Public Econ. 26 (June 1985): $147-67$.

Benveniste, Lawrence. "Two Notes on the Malinvaud Condition for Efficiency of Infinite Horizon Problems." J. Econ. Theory 12 (April 1976): 338-46.

Brock, William A., and Gale, David. "Optimal Growth under Factor Augmenting Progress." $J$. Econ. Theory 1 (October 1969): 229-43.

Brock, William A., and Mirman, Leonard J. "Optimal Growth and Uncertainty: The Discounted Case." J. Econ. Theory 4 (June 1972): 479-513.

Brock, William A., and Turnovsky, Stephen J. "The Analysis of Macroeconomic Policies in a Perfect Foresight Equilibrium." Internat. Econ. Rev. 22 (February 1981): 179-209.

Cass, David. "Optimum Growth in an Aggregative Model of Capital Accumulation." Rev. Econ. Studies 32 (July 1965): 233-40.

Corbo, Vittorio, Krueger, Anne O., and Ossa. Fernando, (eds). Export Oriented Development Strategies: The Success of Five Newly Industrializing Countries. Boulder and London: Westview Press, 1985.

Debreu. Gerard E. "Valuation Equilibrium and Pareto Optimality." Proc. Nat. Acad. Sci. 40 (1954): 588-92.

Gale, David, and Sutherland, William R. "Analysis of a One Good Model of Economic Development." In Mathematies of the Decision Sciences, edited by George Dantzing and Arthur Veinott. Providence: American Mathematical Society, 1968.

Judd, Kenneth L. "The Short-Run Analysis of Fiscal Policy in a Simple Perfect Foresight Model." J.P.E. 93 No. 2 (April 1985): 298-319.

"Capital Gains Taxation by Realization in Dynamic General Equilibrium." Working Paper. Evanston, Illinois: Northwestern Univ., 1986.

"The Welfare Cost of Factor Taxation in a Perfect Foresight Model." J.P.E. 95 (August 1987): 695-709.

Krueger, Anne. "The Importance of Economic Policy in Development: Contrasts Between Korea and Turkey." Working paper. Cambridge, Mass.: NBER, 1986.

- Liberalization Attempts and Consequences. Cambridge, Mass.: Bollinger Publishing Co. (for NBER), 1978.

Lucas, Robert E., Jr. "On the Mechanics of Economic Development." J. Monelary Econ. 22 (July, 1988): $3-42$.

Makin, John H., and Shoven, John B. "Are There Lessons for the United States in the Japanese Tax System." In Contempomry Economic Problems: Deficits, Taxes, and Economic Adjustments, edited by Phillip Cagan. American Enterprise Institute, 1987. 
Prescott, Edward C., and Mehra, Rajnish. "Recursive Competitive Equilibrium: The Case of Homogeneous Households." Econometrica 48 (September 1980): 1365-79.

Rebelo, Sergio. "Long Run Policy Analysis and Long Run Growth." Working Paper. Rochester, N.Y.: Univ. Rochester, 1988.

Reynolds, Lloyd G. Economic Growth in the Thind World New Haven and London: Yale University Press, 1985.

Romer, Paul. "Growth Based on Iucreasing Returns Due to Specialization." A.E.R. Papers and Proc. 77 (May 1987): 56-62.

_- "Increasing Returns and Long-Run Growth." J.P.E. 94 (October 1986): 1002-37.

Scheinkman, Jose A. "On Optimal Steady States on Sector Growth Models when Utility is Dis. counted." J. Econ. Theory 12 (February 1976): 11-30.

Schmitz, James. "Imitation, Entrepreneurship, and Long-Run Growth." J.P.E. 97 (June 1989): $721-39$.

Shell, Karl. "A Model of Inventive Activity and Capital Accumulation." In Essays on the Theory of Optimal Economic Growth, edited by Karl Shell. Cambridge, Mass.: MIT Press, 1967.

. "Inventive Activity, Industrial Organization and Economic Activity." in James A. Mirrlees and Nicholas H. Stern (eds.) Models of Economic Growth London: The Macmilian Press Ltd., 1973.

Solow, Robert E. "A Contribution to the Theory of Economic Growth." Q.J.E. 70 (February 1956): 65-94.

"Technical Cliange and the Aggregate Production Function." Rev. Econ. Stat. 39 (August 1957): 312-20.

Stokey, Nancy L. "Learning by Doing and the Introduction of New Goods." J.P.E. 96 (August 1988): 701-17.

Stokey, Nancy L., Lucas, Robert E., and Prescott, Edward C. Recursive Methods in Economic Dynamics. Cambridge, Mass.: Harvard Univ, Press, (forthcorning) 1989. 


\section{Appendix}

In this appendix we prove that if we compare two planner's problems, one for the original economy and one for the modified economy of Section 5 , the latter has a lower investment rate. Consider first the original problem

$$
\begin{array}{ll}
\text { (OP) } \max & \Sigma_{t=0}^{n} \beta^{t} u\left(c_{t}\right) \\
\text { subject to } & c_{t}+x_{t} \leq f\left(k_{t}\right), \\
& k_{t+1}=(1-\delta) k_{t}+x_{t},
\end{array}
$$

Let the optimal investment function be $g_{n}(k, 0)$ (to indicate that the tax rate $t$ is zero) when the planning horizon is $n$ periods and the initial capital stock is $k$. Denote the optimal consumption by $c_{n}(k)$. Thus,

$$
c_{n}(k)=f(k)-g_{n}(k, 0)
$$

A standard result for the one sector growth model is that $c_{n}(k)$ is an increasing function of $k$ ( see Stokey, Lucas, and Prescott [1989].)

Next, consider the modified problem

$$
\begin{array}{ll}
(\mathrm{MP}) \max & \Sigma_{t=0}^{n} \beta^{t} u\left(c_{t}\right) \\
\text { subject to } & c_{t}+x_{t} \leq \hat{f}\left(k_{t}\right)+z_{t} \\
& k_{t+1}=(1-\delta) k_{t}+x_{t}
\end{array}
$$

where $\left\{z_{t}\right\}$ is taken to be exogenous, $\hat{f}(k)=(1-\tau) f(k)+\tau \delta_{\tau} k_{1}$ and $\delta_{\tau} \leq f^{\prime}(k)$ for all $k$.

Let the optimal investment function for this problem, when $z_{1}$ is equal to its fixed point $\left[z_{t}=\tau\left(f\left(k_{t}(z)\right)-\delta_{r}\right)\right]$ and the planning horizon is $n$ periods, be $g_{n}(k, \tau)$. We want to show that $g_{n}(k, 0) \geq g_{n}(k, \tau)$ for all $k$ and $n$.

Proposition A.1: Asgume that the conditions for existence are satisfied. Then for all $\boldsymbol{n}$ and $k$, $g_{n}(k, 0) \geq g_{n}(k, \tau)$

Proof: The argument is by induction. Consider the case $n=1$ and suppose to the contrary that $g_{1}(k, \tau)>g_{1}(k, 0)$. Because investment is positive for the (MP) economy, the first order condition is

$$
u^{\prime}\left(c_{0}^{\tau}\right)=\beta u^{\prime}\left(c_{1}^{\tau}\right) \hat{f}^{\prime}\left(k_{1}^{\top}\right)
$$


However, we have $c_{0}^{\prime}\left\langle c_{0}\right.$ and $\left.c_{\mathrm{I}}^{\mathrm{r}}\right\rangle c_{\mathrm{l}}$ because $\left.k_{\mathrm{I}}\right\rangle k_{\mathrm{t}}$. Thus,

$$
u^{\prime}\left(c_{1}^{r}\right) \beta f^{\prime}\left(k_{l}^{r}\right)=u^{\prime}\left(c_{0}^{r}\right)>u^{\prime}\left(c_{0}\right) \geq \beta u^{\prime}\left(c_{1}\right) f^{\prime}\left(k_{1}\right)
$$

Because $u^{\prime}\left(c_{l}^{r}\right)>u^{\prime}\left(c_{0}\right)$, we must have $f^{\prime}\left(k_{i}^{r}\right)>f^{\prime}\left(k_{1}\right)$. But $f^{\prime}(k)=f^{\prime}(k)+r\left(\delta_{r}-f^{\prime}(k)\right)$. Therefore, the previous condition is equivalent to $r\left(\delta_{r}-f^{\prime}(k)\right)>0$ which is a contradiction.

Vext assume that the statement is true for $n$ and we show that it also holds for $n+1$.

We need to consider two cases.

case a: $k_{j} \geq k_{j} \quad j=1,2, \ldots, n$.

To prove this, suppose to the contrary that $g_{n+1}(k, \tau)>g_{n+1}(k, 0)$. Therefore, we must have $g_{n+1}(k, \tau)>0$. Consequently, if we construct the function $h(\epsilon)$ given by:

$h(\epsilon) \equiv u\left[\hat{f}\left(k_{0}^{\gamma}\right)+z_{0}-g_{n+1}\left(k_{0}^{\top}, \tau\right)+\epsilon\right]+\beta u\left[f\left(k_{i}^{\top}-\epsilon\right)+z_{1}-g_{n}\left(k_{1}^{\top}, \tau\right)\right]+\ldots+\beta^{n} u\left[\hat{f}\left(k_{n}^{r}-(1-\delta)^{n-1} \epsilon\right)+z_{n}-g_{0}\left(k_{n}^{r}, \tau\right)\right]$.

it attains a maximum at $\epsilon=0$. The first order condition is simply

$$
u^{\prime}\left(c_{0}^{\gamma}\right)=\Sigma_{j=1}^{n} \beta^{j}(1-\delta)^{j-1} u^{\prime}\left(c_{j}^{\gamma}\right) \hat{f}^{\prime}\left(k_{j}^{\top}\right)
$$

Notice that, for all $k_{1} f^{\prime}(k)<f^{\prime}(k)$. Therefore,

$$
u^{\prime}\left(c_{0}^{\gamma}\right)<\Sigma_{j=1}^{n} \beta^{j}(1-\delta)^{j-1} u^{\prime}\left(c_{j}^{\top}\right) f^{\prime}\left(k_{j}^{\top}\right)
$$

By the inductive hypothesis we have that

$$
c_{j}^{\top}\left(k_{j}^{\top}\right)=f\left(k_{j}^{\top}\right)-g_{n+1-j}\left(k_{j}^{\top}, \tau\right) \geq f\left(k_{j}^{\top}\right)-g_{n+1-j}\left(k_{j}^{J}, 0\right)=c_{j}\left(k_{j}^{\top}\right) .
$$

\section{Therefore,}

$$
u^{\prime}\left(c_{0}^{\gamma}\right)<\Sigma_{j=1}^{n} \beta^{j}(1-\delta)^{j-1} u^{\prime}\left(c_{j}\left(k_{j}^{\top}\right)\right) f^{\prime \prime}\left(k_{j}^{\top}\right)
$$

By monotonicity of $c_{j}$, concavity of $u$ and $f$, and the asumption that $k_{j} \geq k_{j}$, we have

$$
u^{\prime}\left(c_{0}^{j}\right)<\sum_{j=1}^{n} \beta^{j}(1-\delta)^{j-1} u^{\prime}\left(c_{n+1-j}\left(k_{j}\right)\right) f^{\prime}\left(k_{j}\right)
$$


On the other hand, the optimal solution for the problem (OP) requires

$$
u^{\prime}\left(c_{0}\right) \geq \sum_{j=1}^{n} \beta^{j}(1-\delta)^{j-1} u^{\prime}\left(c_{j}\left(k_{j}\right)\right) f^{\prime}\left(k_{j}\right)
$$

These two equations together imply that $u^{\prime}\left(c_{0}\right)>u^{\prime}\left(c_{0}^{\tau}\right)$ or that $f(k)-g_{n+1}\left(k_{1}, 0\right)<f(k)-g_{n+1}(k, r)$ which is a contradiction.

case b: For some $1<t<n, \quad k_{i}^{T}<k_{t}$.

Note that since $k_{\mathrm{f}}^{\top}>k_{1}$ by hypothesis this case requires that for some $j+1<t, x_{j+1}>0$. We now argue that if $x_{j+1}>0$ then $x_{s}>0 \quad s=0,1 \ldots \ldots$. Without loss of generality assume that $j+1$ is the first time that $x_{t}>0$. Then a standard first order condition for the growth problem is

$$
u^{\prime}\left(c_{j}\right) \geq u^{\prime}\left(c_{j+1}\right) \beta\left[f^{\prime}\left(k_{j+1}\right)+1-\delta\right]>u^{\prime}\left(c_{j+1}\right)
$$

where the last inequality follows from condition $G$. Thus $c_{j+1}>c_{j}$ and $c_{j+1}+x_{j+1}>c_{j}+$ $x_{j}$ or $f\left(k_{j+1}\right)>f\left(k_{j}\right)$. This, however, requires $k_{j+1}>k_{j}$ which contradicts $x_{j}=0$.

It then follows that $x_{0}$ and $x_{1}$ are positive. In this case the Euler equation is:

$$
u^{\prime}\left(c_{0}\right)=\beta u^{\prime}\left[f\left(k_{1}\right)-g_{n}\left(k_{1}, 0\right)\right]\left[f^{\prime}\left(k_{1}\right)+1-\delta\right]
$$

Because $x_{0}^{+}>0$ by assumption, we have

$$
u^{\prime}\left(c_{0}^{\tau}\right)=\beta u^{\prime}\left[f\left(k_{1}^{\tau}\right)-g_{n}\left(k_{1}^{\tau}, \tau\right)\right]\left[\dot{f}^{\prime}\left(k_{1}^{\tau}\right)+1-\delta\right]
$$

By the inductive hypothesis $g_{n}\left(k_{1}^{\top}, \tau\right) \leq g_{n}\left(k_{1}^{T}, 0\right)$. Also, $f\left(k_{1}^{r}\right)<f^{\prime}\left(k_{1}^{\top}\right)$. Thus,

$$
u^{\prime}\left(c_{0}^{r}\right)<\beta u^{\prime}\left[f\left(k_{1}^{r}\right)-g_{n}\left(k_{1}^{r}, 0\right)\right]\left[f^{\prime}\left(k_{1}^{r}\right)+1-\delta\right]
$$

If $k_{1}^{r}>k_{1}$ we have $u^{\prime}\left(c_{0}\right)<u^{\prime}\left(c_{0}^{r}\right)$. These inequalities imply:

$$
u^{\prime}\left[f\left(k_{1}^{\top}\right)-g_{n}\left(k_{1}^{\top}, 0\right)\right]\left[f^{\prime}\left(k_{1}^{\top}\right)+1-\delta\right]>u^{\prime}\left[f\left(k_{1}\right)-g_{n}\left(k_{1}, 0\right)\right]\left[f^{\prime}\left(k_{1}\right)+1-\delta\right]
$$

Given that each term is monotone decreasing in $k_{1}$ the inequality implies $k_{1}^{\top}<k_{1}$, which is a contradiction.

To finalize the proof, standard arguments (see Stokey, Lucas and Prescott [1989]) can be used to show that the infinite horizon investment rules for (MP) and (OP) are given by $\lim _{n \rightarrow \infty} g_{n}(k, \tau)$ and $\lim _{n \rightarrow \infty} g_{n}(k, 0)$, respectively.

Q.E.D. 